\title{
PENGELOLAAN KELOMPOK BELAJAR USAHA (KBU) MENJAHIT DI PKBM ASSOLAHIYAH KARAWANG
}

\author{
Adi Nugroho \\ Program Studi Pendidikan Luar Sekolah Universitas Singaperbangsa Karawang, \\ Jl. HS. Ronggo Waluyo, Telukjambe Timur, Karawang, Jawa Barat, Indonesia \\ adisajalahh@gmail.com
}

\begin{abstract}
Received: April, 2021; Accepted: Mei, 2021

This study aims to describe the planning process, implementation, and results of the Sewing Business Learning Group (KBU) program organized by PKBM Assolahiyah Karawang. The background of this $\mathrm{KBU}$ program is the problems of unemployment, poverty, and high dropout rates in the Cilamaya Kulon District. This research use a descriptive qualitative approach. The research subjects were four people, consisting of two learning citizens, one manager, and one tutor. The data collection technique uses the technique of observation, interview, and documentation study. Data analysis was carried out by identifying the collected data then synthesized and compiled. The results of this study indicate that (1) planning for the KBU program begins with identifying needs, determining objectives, targets, infrastructure, instructors, and program funds; (2) the implementation process is held twice a year, the number of meetings is 22 times using practical methods, lectures and discussions; (3) the results of the KBU program show that learning citizens are skilled in making T-shirts, House Dress, Robe, Shirt, Change up, Making Masks, and Shrinking Clothes and are skilled in other sewing products.
\end{abstract}

Keywords: Management, Business Learning Group, Sewing

\begin{abstract}
Abstrak
Penelitian ini memiliki tujuan untuk mendeskripsikan proses perencanaan, pelaksanaan dan hasil dari program Kelompok Belajar Usaha (KBU) Menjahit yang diselenggarakan oleh PKBM Assolahiyah Karawang. Program KBU ini dilatar belakangi dengan adanya masalah pengangguran, kemiskinan dan tingginya angka putus sekolah di Kecamatan Cilamaya Kulon. Penelitian ini menggunakan pendekatan deskriptif kualitatif. Subyek penelitian berjumlah empat orang, terdiri dari dua orang warga belajar, satu orang pengelola dan satu orang tutor. Teknik pengumpulan data menggunakan Teknik Observasi, Wawancara dan Studi Dokumentasi. Analisis data dilakukan dengan mengidentifikasi data yang dikumpulkan kemudian disintesiskan dan disusun. Hasil penelitian ini menunjukan bahwa (1) perencanaan program KBU diawali dengan melakukan identifikasi kebutuhan, menentukan tujuan, sasaran, sarana prasarana, instruktur, dan dana program; (2) proses pelaksanaan diselenggarakan dua kali dalam setahun, jumlah pertemuan 22 kali dengan menggunakan metode praktik, ceramah dan diskusi; (3) hasil program KBU menunjukan warga belajar terampil dalam membuat pakaian kaos, daster, gamis, kameja, vermak, membuat masker, dan mengecilkan pakaian serta terampil dalam produk menjahit lainnya.
\end{abstract}

Kata Kunci : Penglolaan, Kelompok Belajar Usaha, Menjahit

How to Cite: Nugroho, A. (2021). Pengelolaan Kelompok Belajar Usaha (KBU) Menjahit di PKBM Ahholahiyah Karawang. Comm-Edu (Community Education Journal), 4(2), 46-56.

\section{PENDAHULUAN}

Provinsi Jawa Barat merupakan provinsi dengan penduduk terbanyak se-Indonesia, berdasarkan data statistik di awal tahun 2020 jumlah penduduk Provinsi Jawa Barat mencapai 49 juta jiwa. Dengan keadaan tersebut, banyak permasalahan yang dihadapi Provinsi Jawa 
Barat, salah satunya pemerataan pendidikan. Usaha dalam mencapai pemerataan pendidikan terus dilakukan baik oleh pemerintahan daerah maupun pusat agar tercapainya kualitas sumber daya manusia yang unggul dan mampu bersaing dengan bangsa lainnya. Berdasarkan United Nation Development Programme (UNDP) dilihat dari tiga indikator indeks pembangunan manusia, yaitu indeks pendidikan, kesehatan dan indeks perekonomian. Adanya Pendidikan Nonformal di Indonesia memberikan kesempurnaan dalam dunia pendidikan dalam upaya mencapai pemerataan pendidikan, khususnya bagi masyarakat yang tidak pernah mengenal pendidikan formal dapat difasilitasi oleh program - program yang diselenggarakan pada jalur pendidikan luar sekolah. Pembangunan dalam suatu negara tentu tidak lepas dari pendidikan, dimana pendidikan mempunyai tujuan untuk mengembangkan potensi masyarakat sehingga mampu membangun bangsa dan negara, hal itu juga termuat dalam Undang-undang No. 20 Tahun 2003 Tentang Sistem Pendidikan Nasional pasal 1 ayat 1, yaitu : "Pendidikan adalah usaha sadar dan terencana untuk mewujudkan suasana belajar dan proses pembelajaran agar peserta didik secara aktif mengembangkan potensi dirinya untuk memiliki kekuatan spiritual keagamaan, pengendalian diri, kepribadian, kecerdasan, akhlak mulia, serta keterampilan yang diperlukan dirinya, masyarakat, bangsa dan negara"

PKBM adalah satuan pendidikan nonformal yang bertujuan untuk memberikan layanan pendidikan bagi masyarakat. Menurut UNESCO defenisi PKBM adalah sebuah lembaga pendidikan yang diselenggrakan di luar sistem pendidikan formal diarahkan untuk masyarakat pedesaan dan perkotaan dengan dikelola oleh masyarakat itu sendiri serta memberi kesempatan kepada mereka untuk mengembangkan berbagai model pembelajaran dengan tujuan mengembangkan kemampuan dan keterampilan masyarakat agar mampu meningkatkan kualitas hidupnya. Adapun layanan program yang ada di PKBM adalah : Keaksaraan, Kesetaraan Paket A, B dan C, Kelompok Bermain, Taman Pengasuhan Anak, SPS PAUD, Pendidikan dan Pelatihan bagi masyarakat, Pemberdayaan Perempuan, Pendidikan Keorangtuaan, Taman Bacaan Masyarakat (TBM), Kelompok Belajar usaha (KBU), Seni, Usaha Produktif PKBM, Pra-Koperasi dan kegiatan Pendidikan Nonformal lainnya yang dapat menunjang keberlangsungan hidup masyarakat.

Program - program yang beragam tersebut diharapkan mampu memenuhi kebutuhan pendidikan di masyarakat sebagai bekal dalam tanggung jawabnya dikehidupan sehari-hari. Dalam upaya membangun masyarakat yang lebih berdaya guna dan berdaya hasil tersebut, PKBM Assolahiyah hadir di tengah-tengah masyarakat Cilamaya Kulon yang mayoritas masyarakatnya tidak punya pekerjaan sehingga perekonomian masyarakat tersebut berada di kelas menengah kebawah. Selain keadaan ekonomi tersebut, tingginya angka putus sekolah di Kecamatan Cilamaya Kulon merupakan masalah yang perlu di perhatikan oleh berbagai pihak. Keadaan tersebut memberikan dampak yang cukup besar terhadap kesejahteraan hidup masyarakat Cilamaya Kulon. Dalam upaya meningkatkan kesejahteraan masyarakat Cilamaya Kulon, PKBM Assolahiyah menyelenggarakan program berbasis usaha agar masyarakat putus sekolah serta pengangguran memiliki keterampilan tertentu sehingga bisa bekerja atau berwirausaha. Menurut Kamil (2011:99) "Kelompok belajar usaha yaitu suatu kegiatan membelajarkan warga masyarakat untuk mengejar ketinggalan di bidang usaha, dengan cara bekerja, belajar dan berusaha, guna memperoleh mata pencaharian sebagai sumber penghasilan yang layak. KBU sebagai salah satu program pendidikan masyarkat yang di dalamnya ada kegitan belajar dan berusaha. Melalui KBU, di tumbuhkan dan di kembangkan pengetahuan, ketrampilan dan sikap berusaha dari warga belajar sehingga memiliki mata pencaharian sebagi sumber penghasilan, demikian pula KBU akan memberikan pengaruh terhadap pertumbuhan mata pencaharian masyarkat di sekitarnya, 
dengan kata lain Kelompok Belajar Usaha dapat diartikan sebagai suatu kegiatan membelajarkan warga masyarakat untuk mengejar ketinggalan di bidang usaha dengan cara bekerja, belajar, dan berusaha guna memperoleh mata pencaharian sebagai sumber penghasilan yang layak.

Pertumbuhan industri garmen di Kabupaten Karawang memberikan dampak positif dalam industri mejahit dan industri terkait lainnya. Peluang ini ditangkap dengan baik oleh PKBM Assolahiyah diantaranya dengan mempersiapkan sumber daya manusia dengan keterampilan yang memadai di bidang konveksi yaitu dengan menyelenggarakan program kelompok belajar usaha (KBU) menjahit. Hal ini juga membuka kesempatan kepada masyarakat untuk mengikuti program KBU menjahit sehingga membuka kesempatan kepada masyarakat untuk meningkatkan kesejahteraan hidup. Dalam hal ini agar program tersebut berjalan dengan seimbang dan terus berkembang maka diperlukan suatu pengelolaan didalamnya. Pengelolaan yang dimaksud agar terciptanya proses kegiatan belajar mengajar yang dapat mensejahterakan masyarakat dan dapat mencapai tujuan program dengan maksimal. Pengelolaan atau manajemen melibatkan aktivitas - aktivitas koordinasi dan pengawasan terhadap seluruh kegiatan sehingga kegiatan dalam program tersebut dapat berjalan dengan efisien dan efektif. Pengelolaaan dalam satuan pendidikan khususnya di PKBM sangat berperan penting. Karena dengan adanya pengelolaan, menjadikan program - program di PKBM tersebut lebih terencana, terorganisir, terlaksana, dan terkendali dengan maksimal sesuai dengan apa yang diharapkan. Berdasarkan beberapa hal yang telah dipaparkan diatas, penelitian ini bertujuan untuk mendeskripsikan proses perencanaan dan pelaksanaan serta menganalisis hasil dari program KBU menjahit yang diselenggarakan oleh PKBM Assolahiyah Karawang.

\section{METODE PENELITIAN}

Penelitian ini menggunakan metode deskriptif kualitatif. Deskriptif kualitatif adalah jenis penelitian yang berupaya untuk memberikan gambaran secara lengkap mengenai suatu bentuk permasalahan sosial yang terjadi di dalam kehidupan bermasyarakat. Menurut Bogdan dan Taylor (1975:5) dalam Lexy J. Moleong (2016:4) mendefinisikan metodologi kualitatif sebagai prosedur penelitian yang menghasilkan data deskriptif berupa kata - kata tertulis atau lisan dari orang - orang dan perilaku yang dapat diamati. Adapun subjek yang akan di teliti dalam penelitian ini berjumlah empat orang, diantaranya yaitu satu orang pengelola PKBM, satu orang tutor dan dua orang warga belajar. Teknik yang digunakan dalam pengumpulan data dan informasi dari subjek penelitian tersebut menggunakan teknik observasi, wawancara dan studi dokumentasi.

Analisis data dalam penelitian ini melewati beberapa tahapan, diantaranya tahap pertama yaitu pengumpulan data, selanjutnya adalah pemilihan data yang telah dikumpulkan sebelumnya, kemudian memasuki tahap penyajian data yaitu memaparkan data data yang diperoleh dengan menggunakan beberapa teknik pengumpulan data dan terakhir peneliti menarik kesimpulan dan melakukan verifikasi. Secara garis besar, aktivitas analisis data yang digunakan dalam penelitian kualitatif dibagi menjadi beberapa ativitas. Menurut Glaser \& Strauss dalam Lexy J. Moleong (2016:288) mengemukakan model analisis data yang disebut dengan Metode Perbandingan Tetap (Constant Comparative Method). Secara umum proses analisis datanya mencakup : Reduksi data, kategorisasi data, sintesisasi, dan diakhiri dengan menyusun hipotesis kerja. 
Penelitian ini menggunakan metode deskriptif kualitatif. Deskriptif kualitatif adalah jenis penelitian yang berupaya untuk memberikan gambaran secara lengkap mengenai suatu bentuk permasalahan sosial yang terjadi di dalam kehidupan bermasyarakat. Menurut Bogdan dan Taylor (1975:5) dalam Lexy J. Moleong (2016:4) mendefinisikan metodologi kualitatif sebagai prosedur penelitian yang menghasilkan data deskriptif berupa kata - kata tertulis atau lisan dari orang - orang dan perilaku yang dapat diamati. Adapun subjek yang akan di teliti dalam penelitian ini berjumlah empat orang, diantaranya yaitu satu orang pengelola PKBM, satu orang tutor dan dua orang warga belajar. Teknik yang digunakan dalam pengumpulan data dan informasi dari subjek penelitian tersebut menggunakan teknik observasi, wawancara dan studi dokumentasi.

Analisis data dalam penelitian ini melewati beberapa tahapan, diantaranya tahap pertama yaitu pengumpulan data, selanjutnya adalah pemilihan data yang telah dikumpulkan sebelumnya, kemudian memasuki tahap penyajian data yaitu memaparkan data data yang diperoleh dengan menggunakan beberapa teknik pengumpulan data dan terakhir peneliti menarik kesimpulan dan melakukan verifikasi. Secara garis besar, aktivitas analisis data yang digunakan dalam penelitian kualitatif dibagi menjadi beberapa ativitas. Menurut Glaser \& Strauss dalam Lexy J. Moleong (2016:288) mengemukakan model analisis data yang disebut dengan Metode Perbandingan Tetap (Constant Comparative Method). Secara umum proses analisis datanya mencakup : Reduksi data, kategorisasi data, sintesisasi, dan diakhiri dengan menyusun hipotesis kerja.

\section{Wetode Perbandingan Tetap \\ Constant Comparative Method}

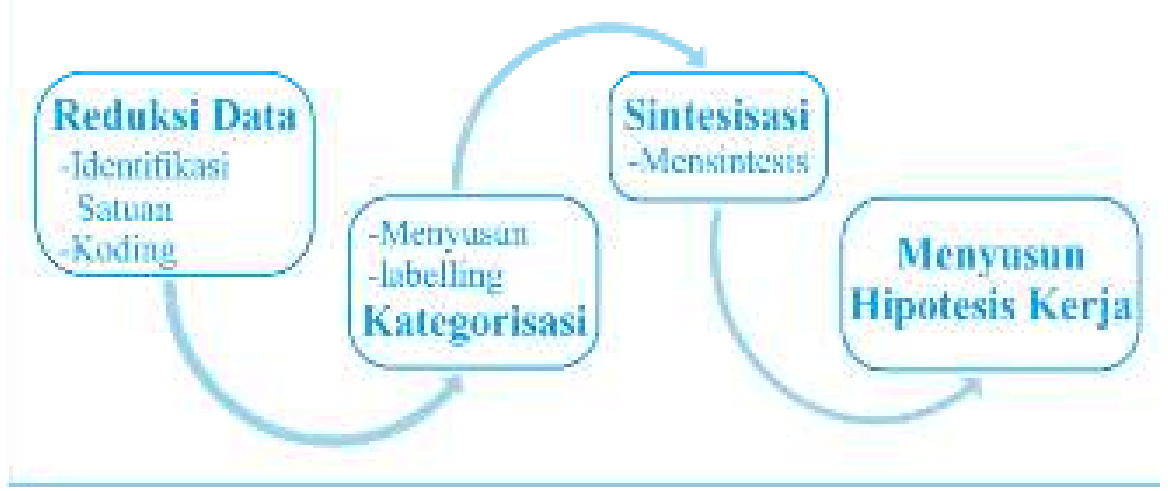

Gambar 1. Bagan Metode Perbandingan Tetap 
50 Nugroho, A. Pengelolaan Kelompok Belajar Usaha (KBU) Menjahit di PKBM Assholahiyah, Karawang

\section{HASIL DAN PEMBAHASAN}

\section{Hasil}

Identitas lembaga PKBM Assolahiyah Karawang adalah sebagai berikut :

$\begin{array}{ll}\text { Nama Lembaga } & : \text { PKBM Assolahiyah } \\ \text { Alamat Lengkap } & : \text { Kp Cilempung RT 21 RW 04 Ds. Pasirjaya } \\ & \text { Kec. Cilamaya Kulon - Karawang 41384 } \\ \text { NPSN } & : \text { P2965541 } \\ \text { No. Izin operasional } & : \text { 421.9/979/PLS-PO } \\ \text { Status Bangunan } & : \text { Milik Sendiri } \\ \text { Notaris } & : \text { Meisyarani, S.H. } \\ \text { NILEM } & : \text { 32.3.10.0002.3.0.0002 } \\ \text { NPWP } & : \text { 30.027.431.9.-433.000 } \\ \text { Akreditasi } & : \text { Terakreditasi “A “ } \\ \text { Tanggal Pendirian } & : \text { 07 Januari 2008 } \\ \text { Status Bangunan } & : \text { milik sendiri } \\ \text { Website } & : \text { https://assolahiyah.sch.id } \\ \text { Email } & : \text { yayasanassolahiyah@gmail.com }\end{array}$

Latar belakang program KBU di PKBM Assolahiyah Karawang berangkat dari kegelisahan ketua PKBM terhadap kesejahteraan masyarakat, banyaknya masyarakat yang tidak/belum bekerja karena terhambat ijazah pendidikan menjadi alasan kuat untuk menyelenggarakan program KBU tersebut. Selain program KBU menjahit, ada beberapa program yang disediakan oleh PKBM Assolahiyah, yaitu : Majlis Ta'lim, Pendidikan Anak Usia Dini (PAUD), Pendidikan Kesetaraan, Pendidikan Kursus/Keterampilan, Kegiatan Usaha Olahan Makanan, dan Pendidikan Lingkungan.

Langkah awal yang dilakukan dalam menentukan program yaitu melakukan identifikasi kebutuhan. PKBM Assolahiyah memutuskan untuk menyelenggarakan program KBU Menjahit karena melihat minat masyarakat yang tinggi terhadap program KBU dan peluang konveksi yang cukup berpotensi di Cilamaya Kulon dengan harapan mampu mengentaskan kemiskinan di daerah Cilamaya Kulon. Menurut Sudjana (2010:186) identifikasi kebutuhan dalam pengembangan program pendidikan nonformal di dasarkan pada empat alasan yaitu sebagai berikut : 1) kebutuhan adalah bagian penting dari kehidupan manusia, 2) keberhasilan seseorang dalam kehidupan lebih banyak dipengaruhi oleh tingkat kemampuan dalam memenuhi kebutuhan, 3) manusia melakukan upaya secara berlanjut dalam kebutuhan itu, 4) dalam kebutuhan sering terdapat kebutuhan - kebutuhan lain yang harus dipenuhi.

Dalam menjalankan program - program yang sudah dirumuskan, PKBM Assolahiyah memutuskan untuk bermitra dengan beberapa instansi sehingga program - program tersebut berjalan lancer dan membuahkan hasil yang maksimal. Mitra kerja yang dikembangkan oleh PKBM Assolahiyah yaitu mitra kerja model ABG-C (Academic, Business, Government \& Community). Adapun mitra kerja model ABG-C bisa dilihat dalam bagan berikut : 


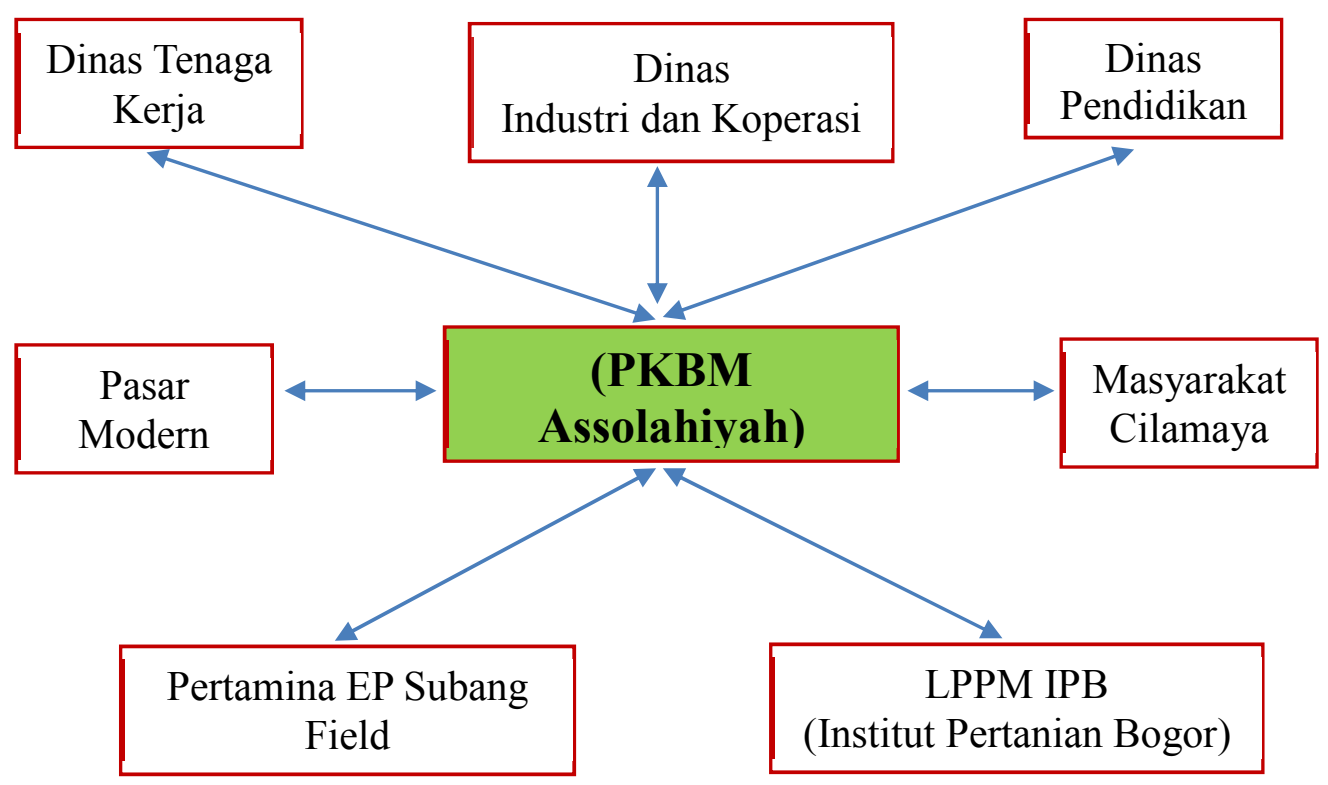

Gambar 2. Bagan Mitra Kerja

Dalam proses pelaksanaan program KBU menjahit, sarana prasarana yang mendukung program tersebut disediakan oleh PKBM Assolahiyah Karawang guna membantu warga belajar mecapai tujuan program dengan maksimal. Sarana yang disediakan oleh PKBM meliputi mesin jahit, buku panduan, papan tulis, kursi dan meja serta sarana pendukung lainnya. Penyediaan sarana prasarana secara menyuluruh oleh PKBM merupakan kebijakan yang diambil oleh pengelola agar mempermudah warga belajar dalam proses KBU tersebut. Berikut merupakan sarana prasarana yang disediakan oleh PKBM Assolahiyah :

Tabel 1. Daftar Sarana Prasarana

\begin{tabular}{|c|c|c|c|}
\hline No & Sarana Prasarana & Banyaknya & Status \\
\hline 1 & Tanah PKBM Assolahiyah & $500 \mathrm{~m}^{2}$ & Milik Sendiri \\
\hline \multirow[t]{8}{*}{2} & Gedung PKBM Assolahiyah & $300 \mathrm{~m}^{2}$ & Milik Sendiri \\
\hline & Ruang Tamu & 1 Ruang & Milik Sendiri \\
\hline & Ruang Sekretariat & 1 Ruang & Milik Sendiri \\
\hline & Ruang Kantor Pengurus & 1 Ruang & Milik Sendiri \\
\hline & Ruang Belajar Teori & 3 Ruang & Milik Sendiri \\
\hline & Ruang Praktek Keterampilan & 1 Ruang & Milik Sendiri \\
\hline & Ruang Usaha & 1 Ruang & Milik Sendiri \\
\hline & Ruang TBM & 1 Ruang & Milik Sendiri \\
\hline \multirow[t]{6}{*}{3} & Sarana Kesekretariatan & & \\
\hline & Kursi Tamu & 2 set & Milik Sendiri \\
\hline & Meja Kursi Kerja & 5 set & Milik Sendiri \\
\hline & Lemari Arsip & 3 unit & Milik Sendiri \\
\hline & Komputer & 3 unit & Milik Sendiri \\
\hline & Printer & 3 unit & Milik Sendiri \\
\hline \multirow[t]{5}{*}{4} & Sarana Pembelajaran & & \\
\hline & Meja Kursi Belajar & 60 unit & Milik Sendiri \\
\hline & Papan Tulis & 5 buah & Milik Sendiri \\
\hline & Buku/modul bahan ajar & 60 set & Milik Sendiri \\
\hline & Mesin jahit & 20 unit & Milik Sendiri \\
\hline
\end{tabular}


52 Nugroho, A. Pengelolaan Kelompok Belajar Usaha (KBU) Menjahit di PKBM Assholahiyah, Karawang

Metode pembelajaran pada dasarnya dapat diartikan sebagai cara - cara yang perlu dipilih dan digunakan untuk mengoptimalkan ketercapaian tujuan pembelajaran. Dengan kata lain, metode pembelajaran merupakan serangkaian cara untuk mengoptimalkan proses dan hasil belajar peserta didik. Menurut Safuri Musa (2010:63) ada beberapa metode/teknik yang dapat di terapkan dalam memfasilitasi warga belajar, diantaranya yaitu : Teknik Diskusi, Curah pendapat, Diskusi kelompok, Simulasi, Bermain peran, Sandiwara, Praktek, Fish Bowl, teknik Delphi dan teknik Permainan. Adapun metode yang digunakan di PKBM Assolahiyah Karawang yaitu menggunakan metode ceramah, praktik dan diskusi. Metode tersebut diterapkan dalam proses pembelajaran yang dilaksanakan setiap minggunya. Adapun pembagian waktu pertemuan di musyawarahkan secara bersama - sama dengan warga belajar, hal itu dilakukan untuk menyesuaikan waktu dengan aktivitas keseharian warga belajar sendiri.

Berikut merupakan daftar pendidik dan tenaga kependidikan di PKBM Assolahiyah pertahun 2020 :

Tabel 2. Daftar Pendidik dan Tenaga Kependidikan

\begin{tabular}{|c|l|l|c|c|}
\hline No & \multicolumn{1}{|c|}{ Nama } & \multicolumn{1}{|c|}{ Alamat } & Pendidikan Terakhir & Jabatan \\
\hline 1 & Heru Saleh & Desa Pasirjaya & S2 & Pengelola \\
\hline 2 & Hendi Sukma Satria & Desa Pasirjaya & SMA & Operator \\
\hline 3 & Abdul Lathif & Desa Pasirjaya & SMA & Tutor \\
\hline 4 & Agus Teguh Wibowo & Desa Pasirjaya & S1 & Tutor \\
\hline 5 & Ahmad Sopandi & Desa Pasirjaya & S1 & Tutor \\
\hline 6 & Aris Krisno & Desa Pasirjaya & S1 & Tutor \\
\hline 7 & Atim Zulkarnaen & Desa Muktijaya & SMA & Tutor \\
\hline 8 & Deni Husniawan & Desa Pasirjaya & S1 & Tutor \\
\hline 9 & Enok & Desa Pasirukem & SMA & Tutor \\
\hline 10 & Fiyan Oktavianto & Desa Pasirjaya & SMA & Tutor \\
\hline 11 & Hamzah & Desa Pasirjaya & S1 & Tutor \\
\hline 12 & Iis Suryani & Desa Pasirjaya & S1 & Tutor \\
\hline 13 & Samsudin & Desa Pasirjaya & SMA & Tutor \\
\hline 14 & Juju Juariah & Desa Bayur Kidul & S1 & Tutor \\
\hline 15 & Siti Marini & Desa Pasirjaya & S1 & Tutor \\
\hline 16 & Siti Shofuroh & Desa Pasirjaya & S1 & Tutor \\
\hline 17 & Syaeppudin & Desa Sukatani & SMA & Tutor \\
\hline 18 & Tri Haryanti & Desa Pasirjaya & S1 & Tutor \\
\hline 19 & Tri Heryanto & Desa Pasirjaya & SMA & Tutor \\
\hline 20 & Yuyun Yunaeni & Desa Pasirjaya & SMA & Tutor \\
\hline 21 & Inu Nanang Ginanjar & Desa Pasirjaya & SMA & Tutor \\
\hline & & & \\
\end{tabular}

\section{Pembahasan}

Berdasarkan pada hasil penelitian, maka pembahasan penelitian dapat dikaji sebagai berikut :

1. Perancanaan Program KBU Menjahit di PKBM Assolahiyah Karawang

Pada proses perencanaan yang dilakukan oleh PKBM Assolahiyah Karawang dalam program KBU menjahit ada beberapa tahap yang dilakukan yaitu : identifikasi kebutuhan, merumuskan tujuan, sasaran, sarana prasarana, media pembejalaran, instruktur, output program dan penyiapan dana. Identifikasi dilakukan dengan mengumpulkan informasi langsung dari warga masyarakat dan para tokoh yang ada di Kecamatan Cilamaya Kulon. 
Cilamaya Kulon sendiri berada di pesisir Karawang, dengan keadaan tersebut, sosiologi masyarakat Cilamaya Kulon sangat ramah dan masih kental dengan sifat masyarakat pedesaan. Hal tersebut memudahkan proses identifikasi, sehingga proses identifikasi yang dilakukan tidak memakan waktu lama, dalam waktu 1 bulan PKBM Assolahiyah sudah memperoleh informasi yang berharga. Setelah proses identifikasi kebutuhan selesai, selanjutnya mulai menganalisis SDA yang ada di Cilamaya Kulon, kemudian menganalisis kebutuhan - kebutuhan yang mendukung program KBU menjahit. Adapun dana yang digunakan untuk penyelenggaraan program ini berasal dari mitra kerja baik itu pemerintah atau CSR perusahaan. Bilamana dana dari mitra kerja PKBM tidak mencukupi untuk program tersebut, dana tambahan berasal dari swadaya warga belajar. namun sejauh ini dana dari mitra kerja mampu menutup program KBU menjahit sehingga masyarakat yang hendak mengikuti program KBU ini tidak dipungut biaya. Hasil dan kebermanfaatan program ini sangat penting sehingga dalam proses perencanaan, hasil akhir pun merupakan kajian yang tidak kalah penting dengan kajian yang lainnya. Oleh karenanya segala hal yang mendukung dalam tercapainya tujuan program semuanya di musyawarahkan dengan baik dalam proses perencanaan agar tercapainya dengan maksimal.

Setelah melakukan persiapan dengan matang, rancangan program tersebut disosialisasikan kepada masyarakat, melalui terjun langsung dan sosial media. Sosialisasi juga dilakukan kepada ibu - ibu yang menyekolahkan anaknya di PAUD Alam Alfirdaus. Kepala sekolah PAUD Alam alfirdaus mensosialisasikan mengenai program tersebut dan menghimbau agar mengikuti program tersebut, selanjutnya sosialisasi juga dilakukan kepada keluarga dan teman instruktur. Hal tersebut lumayan efektif, karena keluarga atau teman yang dihubungi pada akhirnya melakukan sosialisasi kembali kepada keluarganya dan teman yang lainnya, sehingga proses tersebut sangat membantu dalam sosialisasi program KBU. Adapun hambatan yang dirasakan yaitu kurangnya kesadaran masyarakat terhadap pendidikan keterampilan. Sehingga minat mereka terhadap program KBU tidak terlalu antusias, tetapi seiring berjalannya waktu hambatan ini sedikit teratasi setelah melihat suksesnya para lulusan dari program ini. Sehingga ketika gelombang selanjutnya minat masyarakat terhadap program KBU ini bertambah.

2. Pelaksanaan program KBU menjahit di PKBM Assolahiyah Karawang

Pelaksanaan program KBU Menjahit di PKBM Assolahiyah ini dilaksanakan langsung di Gedung PKBM Assolahiyah Karawang sebanyak 2 kali dalam 1 tahun. Gelombang pertama pada 6 bulan pertama dan gelombang kedua dilaksanakan 6 bulan selanjutnya. Program KBU menjahit ini dilaksanakan antara bulan 3 - 5 dan bulan 9 - 11 yang dilaksanakan sebanyak 22 kali pertemuan untuk 1 gelombang. Dalam 1 minggu program KBU ini melaksanakan 2 sampai 4 kali pertemuan di hari dan jam yang sudah disepakati bersama warga belajar.

Persentase pembelajaran antara teori dan praktik sekitar 30\% dan $70 \%$ dari lama waktu sekali pertemuan, yaitu 2 jam. Durasi 2 jam tersebut merupakan waktu maksimal dalam sekali pertemuan yang sudah ditentukan oleh pengelola. Kadang waktu 2 jam tersebut tidak sepenuhnya digunakan untuk proses pembelajaran dikarenakan warga belajar ketika menginjak 1,5 jam pembelajaran suka merasa pusing. Jadi berdasarkan hal tersebut, waktu pertemuan ditentukan maksimal 2 jam untuk satu kali pertemuan. Adapun jumlah warga belajar untuk satu kali program yaitu 20 orang yang dibagi menjadi 2 rombongan belajar dan dibimbing oleh 1 instruktur setiap satu rombel. Dalam 
proses penetapan waktu pelaksanaan program KBU menjahit, hasil identifikasi dan evaluasi dari tahun sebelumnya menjadi salah satu rujukan dalam menentukan waktu pelaksanaan program KBU.

Pada pelaksanaan pembelajaran, pertemuan pertama diisi dengan penjelasan mengenai mesin jahit terlebih dahulu, mulai dari macam - macam jenis mesin serta kegunaanya, memahami bagian - bagian mesin, fungsi dan kelemahannya. Setelah selesai penjelasan mesinnya, dilanjutkan dengan mempelajari teknik dasar dalam menjahit. Mulai dari menggunakan pola lingkaran, pola jigjag, pola lurus dan teknik dasar lainnya yang membantu warga belajar untuk terampil dalam menjahit. Pertemuan - pertemuan selanjutnya dilanjutkan dengan pembelajaran yang lebih mendalam dan bobot muatan materinya lebih tinggi.

\section{Hasil program KBU menjahit di PKBM Assolahiyah Karawang}

Ada beberapa kriteria yang menjadi tolak ukur agar warga belajar dinyatakan lulus dari program KBU menjahit di PKBM Assolahiyah Karawang, diantaranya yaitu dengan tes pengetahuan dan tes keterampilan. Dalam tes pengetahuan warga belajar di tes mengenai pengetahuannya terhadap mesin jahit dan hal - hal yang berhubungan dengan mesin jahit. Untuk tes keterampilan, warga belajar di tes dengan membuat kaos untuk dirinya sendiri. Warga belajar membuat kaos dari nol sampai jadi kaos yang pas dan rapih untuk dirinya sendiri. Pengetahuan dan keterampilan jadi penilaian penting yang diterapkan kepada warga belajar untuk lulus dari program KBU menjahit di PKBM Assolahiyah Karawang. Adapun bilamana warga belajar tidak lulus dalam kedua ujikom tersebut, maka beberapa tindakan diambil oleh PKBM Assolahiyah mengenai kejadian tersebut, yaitu diadakan pertemuan tambahan dengan materi fokus kepada kekurangan - kekurangan yang ditemukan sewaktu tes ujikom, pertemuan ini dilakukan sampai warga belajar dinyatakan lulus. Salah satu poin dalam uji pengetahuan yaitu minimal warga belajar memahami kelemahan - kelemahan mesin jahit yang mereka operasikan agar ketika sudah lulus nanti mampu memperbaiki permasalahan - permasalahan kecil dari mesin jahit tersebut. Selain hal tersebut, hasil dari program KBU menjahit yaitu warga belajar tentunya terampil dalam proses jahit - menjahit, baik itu mengecilkan pakaian, memperbaiki resleting, menjahit tas, macam - macam pakaian, dan produksi lain yang dihasilkan dengan mesin jahit.

Selain terampil dalam dunia menjahit, warga belajar mendapatkan bimbingan lanjutan ketika sudah lulus. Bimbingan tersebut disesuaikan dengan pilihan warga belajar sendiri ketika sudah lulus, apakah bekerja di orang lain atau membuka usaha mandiri. Bagi warga belajar yang hendak bekerja, warga belajar tersebut di magangkan ke konveksi yang sudah menjalin kerja sama dengan PKBM Assolahiyah. Sedangkan untuk warga belajar yang hendak membuka usaha mandiri, PKBM Assolahiyah menyediakan mesin jahit dan peralatan jahit lainnya sehingga warga belajar tidak kesulitan dalam membeli peralatan mesin jahit. Selain membantu dalam menyediakan alat menjahit, PKBM juga membantu dalam pencarian konsumen atau menyalurkan orderan kepada warga belajar tersebut dengan SOP yang sudah ditentukan. Selain bimbingan tersebut, setelah dinyatakan lulus warga belajar bisa datang kembali ke PKBM ketika ada pembelajaran yang lupa sampai warga belajar tersebut memahami kembali. Selain menguasai berbagai macam teknik menjahi, warga belajar lulusan dari program KBU menjahit PKBM Assolahiyah jadi lebih sabar dan lebih kreatif dalam dunia menjahit. Salah satunya warga belajar memproduksi masker kain 2 lapis dan masker kain 3 lapis ketika pandemi Covid - 19 
melanda Indonesia. Hal tersebut merupakan sebuah kreatifitas yang dipadukan denga analisis peluang yang matang dalam dunia usaha menjahit.

Hasil akhir sebagai tanda bukti bagi masyarakat yang sudah mengikuti program KBU menjahit ini adalah sebuah sertifikat yang menyatakan bahwa masyarakat tersebut sudah mengikuti program KBU menjahit dan terampil dalam menjahit. Sertifikat ini sebagai penguat bahwa masyarakat tersebut terampil dalam menjahit, sertifikat ini sangat berguna bagi warga belajar baik yang memilih untuk bekerja ataupun untuk membuka usaha mandiri dan menjadi kebanggaan tersendiri bagi warga belajar.

\section{KESIMPULAN}

Berdasarkan uraian dari hasil penelitian dan pembahasan yang telah dilakukan, maka peneliti dapat menarik kesimpulan sebagai berikut :

1. Perancanaan Program KBU Menjahit di PKBM Assolahiyah Karawang.

Awal mula terbentuknya perogram KBU menjahit di PKBM Assolahiyah Karawang berangkat dari kegelisahan ketua PKBM terhadap kesejahteraan masyarakat, banyaknya masyarakat yang tidak bekerja karena terhambat ijazah menjadi alasan kuat untuk menyelenggarakan program KBU tersebut. Langkah awal yang dilakukan pada tahap perencanaan yaitu melakukan identifikasi kebutuhan kemudian merumuskan tujuan pelatihan, sasaran, sarana prasarana, media pembejalaran, instruktur, dan penyiapan dana.

2. Pelaksanaan program KBU menjahit di PKBM Assolahiyah Karawang.

Program KBU menjahit dilaksanakan sebanyak 2 gelombang dalam setahun. Setiap gelombang terdiri dari 22 kali pertemuan dengan durasi waktu 120 menit/pertemuan yang dilaksanakan selama 2,5 bulan. Metode pembelajaran yang digunakan yaitu metode praktik, ceramah, dan diskusi. Dalam satu kali pelaksanaan ada 20 warga belajar yang bimbing oleh 2 orang instruktur dimana setiap instruktur memegang 10 warga belajar.

3. Hasil program KBU menjahit di PKBM Assolahiyah Karawang.

Program KBU menjahit ini telah meluluskan 20 orang warga belajar yang terampil dalam menjahit. Beberapa produk yang dihasilkan seperti : pakaian kaos, kameja, gamis, daster, masker, mengecilkan pakaian, memperbaiki resleting, menjahit tas dan produk lainnya. Selain itu, warga belajar juga mendapatkan ijazah sebagai tanda kelulusan secara tertulis dari program KBU menjahit di PKBM Assolahiyah Karawang.

\section{UCAPAN TERIMA KASIH}

Dalam penulisan ini penulis sadari sepenuhnya tidak lepas dari bantuan berbagai pihak baik secara langsung maupun tidak langsung sehingga pada kesempatan yang baik ini dengan rasa hormat penulis mengucapkan banyak terima kasih kepada :

1. Prof. Dr. Sri Mulyani, AK, CA. selaku Rektor Universitas Singaperbangsa Karawang.

2. H. Andrie Chaerul, M.Sc., Ph.D. selaku Dekan Fakultas Keguruan dan Ilmu Pendidikan Universitas Singaperbangsa Karawang.

3. Ahmad Syahid, S.Pd., M.Pd. selaku Koordinator Program Studi Pendidikan Luar Sekolah Fakultas Keguruan dan Ilmu Pendidikan Universitas Singaperbangsa.

4. Heru Saleh, S.Pd., M.Pd selaku pengelola PKBM Assolahiyah Karawang yang telah memberikan informasi, arahan dan ijin kepada penulis untuk melaksanakan kegiatan penelitian di PKBM yang beliau pimpin.

5. Samsudin selaku tutor program KBU menjahit yang telah membantu dalam menggali informasi program KBU menjahit.

6. Warga belajar KBU Menjahit PKBM Assolahiyah. 
56 Nugroho, A. Pengelolaan Kelompok Belajar Usaha (KBU) Menjahit di PKBM Assholahiyah, Karawang

7. Kedua orangtua saya, Bapak Komarudin dan Ibu Enok Maryati yang selalu sabar dan ikhlas dalam mendukung dan mendoakan proses pendidikan saya.

Semua pihak yang tidak dapat penulis sebutkan satu-persatu yang telah memberikan bantuan dalam penyusunan karya ilmiah ini. 


\section{DAFTAR PUSTAKA}

Kamil, Mustofa . (2011). Pendidikan Non Formal Pengembangan Melalui Pusat Kegiatan Belajar Masyarakat (PKBM) di Indonesia (sebuah pembelajaran dari komunikan jepang). Bandung: Alfabeta.

Moleong, L.,J. (2016). Metode Penelitian Kualitatif (Edisi Revisi). Bandung : PT Remaja Rosdakarya.

Sudjana, D. (2004). Manajemen Program Pendidikan : Untuk Pendidikan dan Pengembangan Sumber Daya Manusia. Bandung : Falah Production.

Musa, Safuri. (2010). Seni dan Teknik Fasilitasi Pendidikan Orang Dewasa. Bandung : YPIN Indonesia. 